\title{
Paediatric obesity and renal transplantation: current challenges and solutions
}

\author{
John D. Terrace ${ }^{1} \cdot$ Gabriel C. Oniscu $^{1}$
}

Received: 10 November 2014 /Revised: 27 April 2015 / Accepted: 28 April 2015 / Published online: 28 May 2015

(C) IPNA 2015

\begin{abstract}
The increased incidence of obesity in the paediatric population poses significant challenges to renal transplantation. Whilst the body mass index appears to be widely used as a measure of obesity in adults, there are no standardised definitions in the paediatric population, making comparative analyses difficult. In the paediatric transplant population, obesity is associated with an increased incidence of surgical complications, diabetes, hyperlipidaemia and cardiovascular morbidity, leading to diminished graft function and impacting patient and graft survival. Management of obesity in renal transplantation requires multiple interventions starting with lifestyle and behavioural modification combined with medical and possibly surgical therapies, representing a unique challenge in the childhood setting. In this review we discuss the current challenges of obesity and potential solutions in the setting of paediatric transplantation.
\end{abstract}

Keywords Renal transplantation · Obesity · Paediatric · Graft function $\cdot$ Survival $\cdot$ Management

\section{Introduction}

Obesity represents a significant challenge to modern day healthcare and is estimated to involve in excess of $20 \%$ of the population in developed countries [1]. The interaction with renal transplantation is multifaceted and with an ever growing demand for renal transplantation and as many as $60 \%$ of adult

Gabriel C. Oniscu

gabriel.oniscu@ed.ac.uk

1 Transplant Unit, The Royal Infirmary of Edinburgh, Little France Crescent, Old Dalkeith Road, Edinburgh EH16 4SA, UK patients overweight or obese at the time of transplantation [2], the challenges are significant. Furthermore, in the last decade there has been a growing concern regarding an epidemic of obesity in the childhood and adolescent population. In the UK it has been reported that around one-third of children aged 215 years are overweight or obese and that this proportion is likely to increase in the future ([3]; see Fig. 1). This trend has considerable implications for managing young patients with chronic renal failure facing the need for dialysis and kidney transplantation. Although the impact of obesity in adult renal transplantation has been extensively investigated (and remains subject to heated debate), the problems posed by obesity in paediatric patients have received comparatively little attention in the literature. Furthermore, some of the potential solutions in the adult population are not as relevant for the paediatric transplantation.

Therefore, in this review we discuss the specific challenges of obesity in the paediatric population and the potential solutions in the wider context of managing obesity in transplant recipients.

\section{The metrics of obesity}

The body mass index (BMI) is the most widely used measure of obesity in adult patients due to the ease of calculation [kilogrammes $(\mathrm{kg}) /$ height in metres squared $\left(\mathrm{m}^{2}\right)$ ]. Obesity according to BMI criteria has been further stratified into class I (obese, 30-34.9 kg/m²), class II (morbidly obese, 35-39.9 $\mathrm{kg} / \mathrm{m}^{2}$ ) and class III (very morbidly obese, $>40 \mathrm{~kg} \mathrm{~m}^{2}$ ), with adult transplant recipients in the USA recently comprising $23 \%$ class I, $9 \%$ class II and $2 \%$ class III [4]. In addition to stratifying the population based on weight and height, the BMI classifications share a relationship with clinically relevant end-points, such as cardiovascular mortality, in large 
Fig. 1 Prevalence of obesity in paediatric population in the UK (source: http://www.noo.org.uk/ NOO_about_obesity/child_ obesity/UK prevalence - courtesy of Public Health England)

\section{Trend in the prevalence of obesity Childrenaged 2-10 and 11-15 years; Health Survey for England 1995-2013}

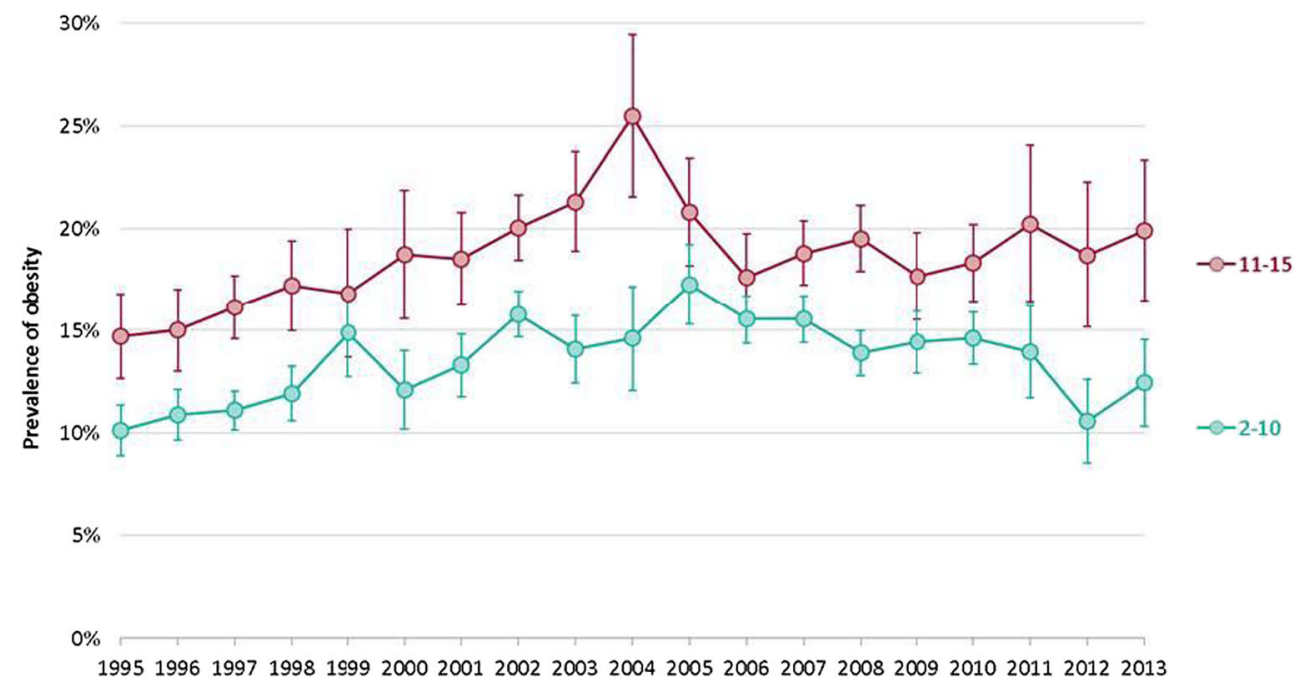

population studies. However, such a correlation cannot be extrapolated to the paediatric population given the age of the patients and the time lag to developing cardiovascular events.

However, in children and adolescents, BMI assessment is more difficult as it changes as children mature. Furthermore, growth patterns are different between boys and girls and, therefore, both the age and sex should be considered to accurately determine the weight of an individual and a population of children (Table 1). BMI thresholds are defined by a specific $z$-score (or centile), which can then be cross-referenced against the specific child growth reference used [5-7]. Several growth references for children have been described, including the UK90 growth reference chart for the UK, sets of cut-off values of BMI by age and sex established by the International Obesity Task Force (IOTF), sets of percentiles of BMI by age and sex specific for U.S. children by the Centers for Disease Control (CDC) and criteria established by the World Health Organisation (WHO), where the latter represent growth standards to provide an indication of optimal growth. However, this method has been criticised given that heavier children require a far greater increase in weight than leaner children to achieve the same score. As an alternative, more recent paediatric studies employ BMI \%, which calculates the difference from the median BMI-for-age, as it is thought to represent as rigorous a calculation as $\mathrm{BMI}$ itself $[5,8]$.

Therefore, an international standardisation of definition, reference population and age- and gender-specific cut-off points has been attempted in order to allow international comparisons and monitor the epidemic of obesity [9]. Despite this attempt, however, the two most widely used references (IOTF and WHO) continue to be discrepant due to the choice of cutoffs and the criteria used to select the population samples.

The calculation of BMI does not differentiate adiposity mass from muscle mass and body water, the proportions of which may vary considerably in the end-stage renal disease population. Therefore, in the adult population other measures have been proposed, such as waist-hip ratio or simply the waist circumference measurement. In the paediatric population, measures such as the waist and upper arm circumference, bio-impedance, skinfold thickness, body fat mass and
Table 1 Clinical definitions of weight status in individual children and for population monitoring

\begin{tabular}{lll}
\hline Clinical definitions of weight status & Individual children & Population measurements \\
\hline Clinically very underweight & $\leq 0.4$ th centile & \\
Clinically low weight & $\leq 2$ nd centile & $\leq 2$ nd centile \\
Clinically healthy weight & $>2$ to $<91$ th centile & $>2$ to $<85$ th centile \\
Clinically overweight & $\geq 91$ st centile & $\geq 85$ st centile \\
Clinically obese & $\geq 98$ th centile & $\geq 95$ th centile \\
Clinically extremely obese & $\geq 99.6$ th centile &
\end{tabular}


percentage body fat have been explored as markers of obesity, but have yet to gain wider acceptance [10].

\section{Access to transplantation}

In the adult population, there has been considerable debate about the access to transplantation according to BMI criteria, and in many national guidelines and centres specific policy limits (such as a BMI of $35 \mathrm{~kg} / \mathrm{m}^{2}$ ) are in place in an attempt to minimise the post-operative morbidity and mortality [11-13]. As yet, this does not appear to have translated into the paediatric setting and, indeed, it would be rather difficult to justify such a policy. This is perhaps a consequence of the less welldefined correlation between paediatric BMI and cardiovascular risk, in addition to a distinct absence of consensus in the adult population regarding the BMI threshold that voids any transplantation benefit. In fact, the survival benefit for transplantation versus dialysis in all BMI groups has often been used as a strong counter-argument to restrictive listing policies. However, it is clear that these debates may have potential implications for paediatric listing criteria, particularly in the older group about to transition to the adult population.

\section{Surgical complications}

It is well established in the adult surgical literature that obesity increases the incidence of peri- and postoperative complications, and there is no reason to predict that this should be different in paediatric renal transplant recipients. Although data specific to the paediatric population are scarce, in adult recipients the incidence of surgical site infection appears to dramatically increase with rising BMI and has been reported to reach $40 \%$ in the very morbidly obese transplant patients [14]. In both paediatric and adult settings, comparatively avascular adipose tissue combined with chronic, pretransplantation uraemia and inflammation impairs wound healing and increases the incidence of wound complications, including a fourfold increased risk of wound infection [15]. Wound complications following renal transplantation are further compounded by the use of certain immunosuppressive drugs, including mammalian target of rapamycin (mTOR) inhibitors, in particular sirolimus, and corticosteroids [16]. The higher risk of wound complications (including dehiscence and subsequent incisional herniation) may be due to an association between obesity and reduced collagen deposition, increased tension of the edges of the fascia, the relative avascular nature of the adipose tissue and obesity-associated vascular impairment resulting in decreased oxygen tension and associated neutrophil oxidative killing.

\section{Graft function}

Adult studies report widely on the strong association between delayed graft function and obesity [17-22]. Some of the reasons for this association may relate to the technical challenges at the time of surgery, including a prolonged anastomotic time leading to longer warm ischaemia duration, whilst others may be related to the type of donor (donation after circulatory death) or the negative impact of higher calcineurin inhibitor doses. Paediatric data in this context are limited, but some preliminary evidence suggests that no such correlation exists in children [23]. However, short-term follow-up studies have shown a reduction in glomerular filtration rate (GFR) in childhood obese renal transplant recipients. In a retrospective single-centre analysis, paediatric recipients who were obese prior to or following transplantation experienced a significant reduction in GFR at 1 year post-renal transplant compared with normal weight patients [7]. However, different immunosuppressive regimes were used during the study period, and their exact impact on the renal function or the development of hypertension (postulated by the authors as causing the poorer function) is unclear. In contrast, in a multivariate regression analysis of interval increases in BMI $z$-score following transplantation, there was no apparent effect of increased weight on estimated GFR [6]. This finding was supported by a 4-year follow-up study of estimated GFR in a large multi-centre UK study of normal, overweight and obese paediatric renal transplant patients [24].

In the adult population, there is conflicting evidence as to whether obesity is related to a higher incidence of acute rejection [19, 25-28]. The available paediatric evidence appears to suggest a similar experience, with little difference in the rate of acute rejection between obese and non-obese patients. In keeping with observations from an earlier work [29], Mitsnefes et al. reported that obese children had an equivalent risk of developing acute rejection as normal weight children in the first year post-transplant [7]. Indeed, similar findings were also reported in a large study of over 6500 children using the North American Paediatric Renal Transplant Cooperative Study (NAPRTCS) registry [23].

\section{Patient and graft survival}

Kidney transplantation prolongs survival [30] and improves the quality of life [31] across all patient groups. In the adult population there is conflicting evidence that a higher BMI is associated with a reduction in graft and patient survival. In a comprehensive analysis from the U.S. Renal Data System (USRDS) of over 50,000 adult patients transplanted over a 10 -year period, there was a distinct association between incrementing BMI, particularly in excess of $26 \mathrm{~kg} / \mathrm{m}^{2}$, and multiple end-points, including patient death, graft loss 
censored for patient death and chronic allograft failure [27]. This study also described a U-shape association between BMI and graft and patient survival, with both being significantly worse at the extremes of BMI when compared with the reference range of $24 \mathrm{~kg} / \mathrm{m}^{2}$ [27]. However, a similar correlation at both ends of the BMI spectrum has not been described in the paediatric population. A recent meta-analysis suggested that in fact the association between BMI and poorer adult patient and graft survival was only present in the early reported studies and has been non-existent in studies conducted during the last 10 years [21] (Fig. 2).

The most robust paediatric data investigating a correlation between obesity and patient and graft survival come from the NAPRTCS of over 6500 children, of whom 3500 and 3100 underwent living-donor or cadaveric renal transplantation, respectively, from 1987 to 2002 [23]. In this study, there was no significant difference between obese and non-obese children in terms of overall graft or patient survival. However, in a subgroup analysis, obesity did have an adverse effect on the survival of children aged 6-12 years who had a greater risk of death than non-obese patients, both for living-donor and deceased donor kidney grafts. The majority of deaths were from cardiopulmonary disease. This study also reported that vascular thrombosis was nearly twice as common in the obese children (19 vs. $10 \%)$. Further analyses are required to confirm these findings, but it would appear that the detrimental effect of obesity might be restricted to certain paediatric groups.

\section{Cardiovascular risk}

In the adult population, a BMI of $>30 \mathrm{~kg} / \mathrm{m}^{2}$ is associated with a $190 \%$ increase in the risk of cardiac events, including angina, myocardial infarction, cardiac death and the need for cardiac re-vascularisation [32], and is strongly correlated with the development of post-transplant hypertension [33]. Hypertension, and especially nocturnal hypertension, is also a considerable problem in paediatric recipients [34]. Although this is most problematic in the first month following transplantation, with $50-70 \%$ of recipients affected, the problem persists despite therapeutic intervention, with a prevalence of around $40 \%$ at the 1-year follow-up and $12 \%$ in the longer term $[6,35]$. The significant impact of an increased BMI on the blood pressure appears to be independent of glucocorticoid exposure [36]. Furthermore, the blood pressure is most significantly elevated in those children with obesity prior to transplantation, compared with normal weight children, or with those developing obesity following transplantation [7].

The mechanism by which obesity leads to hypertension is multifactorial [37] and includes sodium sensitivity, higher
Fig. 2 The overall effect of the body mass index (BMI) on patient survival at 1 year (a) and 5 years (b) after renal transplant and according to the study era (adapted from Nicoletto et al. [21]; used with permission). $M-H$ Metropolis-Hastings algorithm, $C I$ confidence interval a

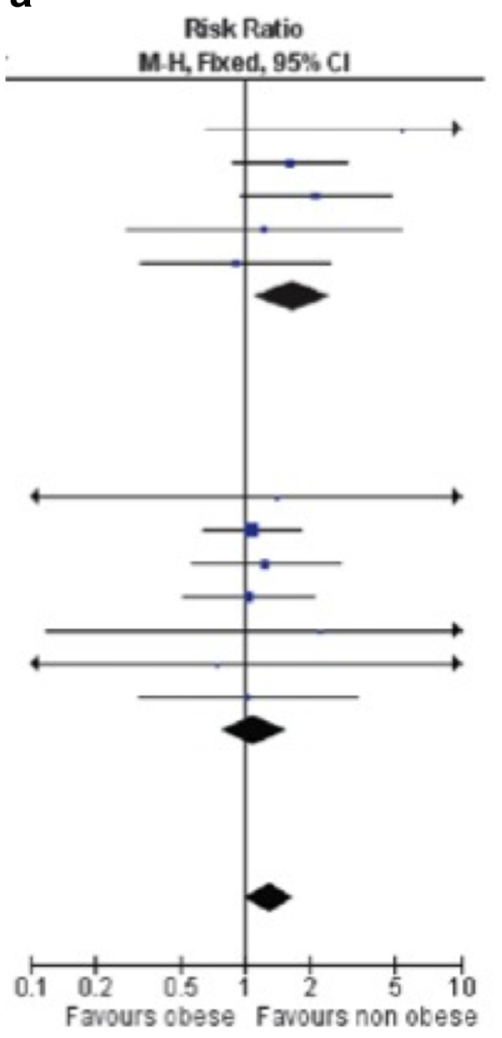

b

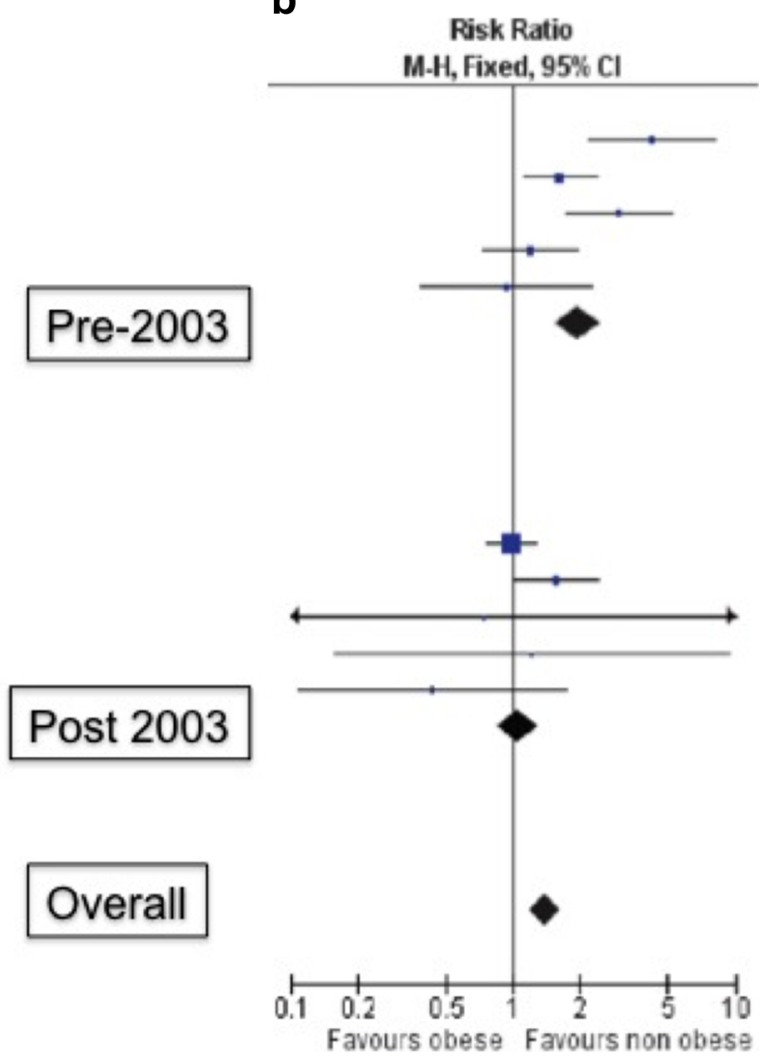


renal sodium reabsorption with impaired pressure natriuresis, increased activity of the renin-angiotensin-aldosterone system, expansion of the extracellular volume and physical compression of the kidneys [38].

Cardiovascular disease, observed most commonly in obese children [23], is the second most common cause of death in paediatric recipients (similar to adult population). Overall, cardiovascular disease has been shown to account for $40 \%$ of all mortality cases in paediatric renal transplantation patients, which is equivalent to a 100 -fold increase compared with an age-matched population [39]. Interestingly, young adults aged 19-39 years with preceding childhood-onset chronic renal failure already managed by dialysis demonstrate advanced coronary and carotid arterial disease [40]. This suggests that arterial disease occurs from the earliest stages of paediatric renal disease, with disease pathogenesis likely a result of atherosclerosis, uraemic arterial sclerosis and uraemic cardiomyopathy. This disease progress strongly supports early transplantation of the paediatric patient.

In a retrospective study of 78 patients aged $1-25$ years who underwent transplantation from 1988 to 2007, a number of dominant cardiovascular risk factors were identified in up to $50 \%$ of patients, including dyslipidaemia, hypertension, hyperglycaemia and excess weight [35]. Although the prevalence of these risk factors decreased in the years following transplantation, they remained abnormally elevated, particularly as the incidence of excess weight increased during this period. The combination of central obesity, dyslipidaemia, hypertension and fasting hyperglycaemia characterises the metabolic syndrome with hyperlipidaemia, insulin resistance or post-transplantation diabetes and weight gain, all common findings following renal transplantation [41-43].

Following renal transplantation, over $50 \%$ of children are classed as overweight or obese compared with approximately $30 \%$ prior to transplantation, with most experiencing rapid and sustained weight gain in the first few months after surgery $[6,24,35]$. The primary driver for post-operative weight gain was found to be excess weight before transplantation.

Several adult studies have suggested that the presence of the metabolic syndrome is a potent predictor of patient and graft outcome $[44,45]$ and that obesity is the primary pathology responsible for the development of the metabolic syndrome [4, 45-48], particularly as adipose tissue secretes adipokines, such as leptin, tumor necrosis factor alpha and interleukin-6 [49]. It is unsurprising, therefore, to see that the prevalence of the metabolic syndrome in children increases following transplantation, affecting between 20 and $40 \%$ of individuals in the first 1-2 years post-transplantation, particularly with prolonged corticosteroid use [50, 51]. It is obesity and its influence on the development of the cardiovascular risk factors comprising the metabolic syndrome that are the central components of the elevated incidence of cardiovascular mortality in paediatric renal transplantation.

\section{Obesity and child growth}

Child growth is an essential outcome of paediatric transplantation as it is linked to better long-term functional outcomes, such as education, employment and marital status. Transplantation restores the child's development to near-normal levels, and catch-up growth is best achieved in children transplanted at a younger age. However, the presence of obesity represents a serious obstacle for normal development. In a cohort study, the authors identified that obese children were younger and shorter and spent more time on dialysis than did non-obese children [23]. A steroid-free regimen protects against increasing obesity post-transplantation and allows a significant growth improvement [52].

\section{Managing obesity in paediatric renal transplantation}

Managing weight gain following transplantation presents a particular challenge in the paediatric setting, not least because of specific social factors figuring prominently in the life of a growing child. With parental involvement, risk modification strategies, including dietary and life-style considerations combined with cholesterol and lipid modification, blood pressure and glycaemia control, are essential. However, this can on occasion be a challenging endeavour, as the risk modification strategies should not only apply to the children but also to their parents. There is a growing body of evidence suggesting that family eating environments [53], parents' own behaviour and even the body weight and physical activity status of child caregivers can influence the development of obesity from a very young age [54]. These findings suggest that the development of obesity in childhood is a multifactorial problem that requires a wide range of environmental and psychosocial factors and behavioural triggers to be addressed in conjunction with genetic predisposition. Of particular importance in the setting of transplantation is a tailored approach to

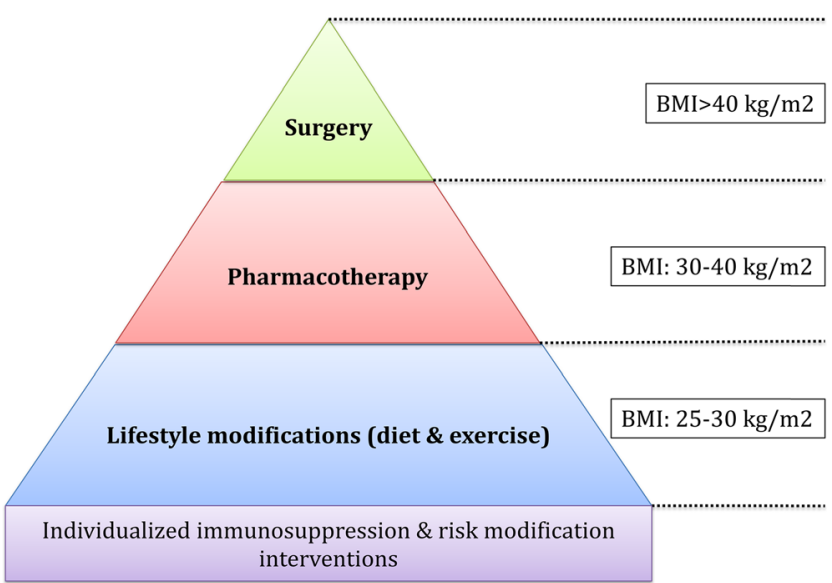

Fig. 3 Pyramid of interventions in the management of obesity in adult renal transplantation. BMI Body mass index 
immunosuppressant drug therapy. This approach should include a limitation on corticosteroid use either with rapid withdrawal or even avoidance, given that prolonged use is closely associated with weight gain and the development of hypertension $[55,56]$. It would also require close monitoring of the graft function, given the increased risk of acute rejection. However, a strategy of antithymocyte globulin induction with calcineurin inhibitor and mycophenolate mofetil maintenance therapy and steroid pulse therapy only for rejection episodes has proved safe and to provide protection against steroidinduced obesity and short stature [52].

There is a step-wise approach to managing obesity in adult renal transplant patients (Fig. 3). Bariatric surgery is the last resort when all other methods have failed to provide the desired weight loss [56]. Arguably, no paediatric recipient should reach this stage if all other measures are carefully implemented with adequate psychosocial support. However, several case reports suggested that bariatric surgery in childhood might have a role, if only in very selected cases $[57,58]$.

\section{Conclusion}

Renal transplantation in the overweight and obese child represents a considerable challenge, which is likely to increase in the coming years. Excess weight translates into a higher risk of surgical complications, an increase in post-transplantation obesity with the associated features of the metabolic syndrome and poorer outcome. Following transplantation, weight gain control is challenging and requires a complex and multimodal approach that necessitates parental support and input. Whether BMI should be used to stratify children at excess risk following transplantation is unclear, and future studies might consider other features of body composition to define obesity. Despite all the challenges associated with obesity, there is a significant survival benefit for transplantation compared with dialysis and, therefore, every effort should be made to offer each child a chance of receiving a kidney transplant at the earliest opportunity.

\section{Table of summary points}

\begin{tabular}{ll}
\hline $\begin{array}{l}\text { Summary } \\
\text { Point }\end{array}$ & Comment \\
1 & BMI assessment in children is more \\
& difficult than in adults as it changes \\
& as children mature. Growth patterns are \\
& different between boys and girls and, \\
& therefore, both the age and sex should be \\
& taken into account to accurately determine \\
& the weight.
\end{tabular}

2

3

4

5

\section{Multiple choice questions (answers are provided following the reference list)}

1) Regarding the definition of obesity in children:

a. Waist-to-hip ratio is the most widely accepted measurement of excess weight;

b. Individual clinical obesity is defined as a weight $\geq 91$ st centile;

c. Clinical overweight in population measurements is defined as a weight $\geq 85$ th centile;

d. Obesity is defined as a BMI in excess of $25 \mathrm{~kg} \mathrm{~m}^{2}$;

e. The reference datasets of the IOTF, CDC and WHO are the least commonly used reference ranges for paediatric obesity.

2) Following renal transplantation in obese paediatric recipients:

a. Wound infection rates are reduced if sirolimus is used;

b. Delayed graft function occurs with equal incidence with increasing levels of obesity;

c. Delayed graft function is primarily caused by the surgeon taking too long to perform the operation;

d. Patient survival is no different from the survival of patients on dialysis;

e. Graft survival is equivalent to that observed in normal weight recipients.

3) Regarding outcomes following renal transplantation in paediatric recipients:

a. The risk of acute rejection is comparable with that of normal weight patients;

b. The risk of patient death is higher in all obese recipients than in normal weight recipients; 
c. The risk of patient death from cardiovascular disease and infection is higher in normal weight recipients;

d. The effects of the metabolic syndrome are eradicated by renal transplantation;

e. The risk of metabolic complications is lower with steroid free immunosuppressive regimens.

4) In considering weight management and transplantation:

a. Obesity in children is influenced by parent' eating habits;

b. Weight gain post-transplantation is lower in pretransplant obese children;

c. Bariatric surgery following transplantation has shown a clear benefit in improving graft survival and is recommended;

d. There is no role for steroid weaning regimens;

e. Psychosocial factors have no role in managing posttransplant obesity.

5) Regarding paediatric renal transplantation:

a. Child and adolescent obesity is not a current concern;

b. Weight tends to fall rather than increase following transplantation in this age group;

c. Younger age and excess pre-transplantation weight is associated with increased weight following transplantation;

d. Graft survival is unaffected by weight in paediatric renal transplantation;

e. Obese children should be deferred from transplantation until they loose weight.

Conflict of interest The authors declare no conflict of interest.

\section{References}

1. Gregg EW, Cheng YJ, Cadwell BL, Imperatore G, Williams DE, Flegal KM, Narayan KM, Williamson DF (2005) Secular trends in cardiovascular disease risk factors according to body mass index in US adults. JAMA 293(15):1868-1874

2. Friedman AN, Miskulin DC, Rosenberg IH, Levey AS (2003) Demographics and trends in overweight and obesity in patients at time of kidney transplantation. Am J Kidney Dis 41(2):480-487

3. Public Health England. Available at: http://www.noo.org.uk/NOO about_obesity/child_obesity/UK_prevalence. Accessed 20 Mar $201 \overline{5}$

4. Lentine KL, Delos SR, Axelrod D, Schnitzler MA, Brennan DC, Tuttle-Newhall JE (2012) Obesity and kidney transplant candidates: how big is too big for transplantation? Am J Nephrol 36(6):575-586

5. Cole TJ, Faith MS, Pietrobelli A, Heo M (2005) What is the best measure of adiposity change in growing children: BMI, BMI \%, BMI $z$-score or BMI centile? Eur J Clin Nutr 59(3):419-425

6. Denburg MR, Pradhan M, Shults J, Jones A, Palmer JA, Baluarte HJ, Leonard MB (2010) Longitudinal relations between obesity and hypertension following pediatric renal transplantation. Pediatr Nephrol 25(10):2129-2139

7. Mitsnefes MM, Khoury P, McEnery PT (2002) Body mass index and allograft function in pediatric renal transplantation. Pediatr Nephrol 17(7):535-539

8. Foster BJ, Martz K, Gowrishankar M, Stablein D, Al-Uzri A (2010) Weight and height changes and factors associated with greater weight and height gains after pediatric renal transplantation: a NAPRTCS study. Transplantation 89(9):1103-1112

9. Cole TJ, Bellizzi MC, Flegal KM, Dietz WH (2000) Establishing a standard definition for child overweight and obesity worldwide: international survey. BMJ 320(7244):1240-1243

10. Degi AA, Kis E, Kerti A, Cseprekal O, Szabo AJ, Reusz GS (2014) Prevalence of obesity and metabolic changes after kidney transplantation: Hungarian pediatric cohort study. Transplant Proc 46(6): 2160-2163

11. Akolekar D, Oniscu GC, Forsythe JL (2008) Variations in the assessment practice for renal transplantation across the United Kingdom. Transplantation 85(3):407-410

12. Segev DL, Simpkins CE, Thompson RE, Locke JE, Warren DS, Montgomery RA (2008) Obesity impacts access to kidney transplantation. J Am Soc Nephrol 19(2):349-355

13. Stenvinkel P, Ikizler TA, Mallamaci F, Zoccali C (2013) Obesity and nephrology: results of a knowledge and practice pattern survey. Nephrol Dial Transplant 28(4):iv99-iv104

14. Lynch RJ, Ranney DN, Shijie C, Lee DS, Samala N, Englesbe MJ (2009) Obesity, surgical site infection, and outcome following renal transplantation. Ann Surg 250(6):1014-1020

15. Humar A, Ramcharan T, Denny R, Gillingham KJ, Payne WD, Matas AJ (2001) Are wound complications after a kidney transplant more common with modern immunosuppression? Transplantation 72(12):1920-1923

16. Giessing M, Budde K (2003) Sirolimus and lymphocele formation after kidney transplantation: an immunosuppressive medication as co-factor for a surgical problem? Nephrol Dial Transplant 18(2): 448-449

17. Cannon RM, Jones CM, Hughes MG, Eng M, Marvin MR (2013) The impact of recipient obesity on outcomes after renal transplantation. Ann Surg 257(5):978-984

18. Doshi MD, Garg N, Reese PP, Parikh CR (2011) Recipient risk factors associated with delayed graft function: a paired kidney analysis. Transplantation 91(6):666-671

19. Gore JL, Pham PT, Danovitch GM, Wilkinson AH, Rosenthal JT, Lipshutz GS, Singer JS (2006) Obesity and outcome following renal transplantation. Am J Transplant 6(2):357-363

20. Molnar MZ, Kovesdy CP, Mucsi I, Bunnapradist S, Streja E, Krishnan M, Kalantar-Zadeh K (2011) Higher recipient body mass index is associated with post-transplant delayed kidney graft function. Kidney Int 80(2):218-224

21. Nicoletto BB, Fonseca NK, Manfro RC, Goncalves LF, Leitao CB, Souza GC (2014) Effects of obesity on kidney transplantation outcomes: a systematic review and meta-analysis. Transplantation 98(2):167-176

22. Weissenbacher A, Jara M, Ulmer H, Biebl M, Bosmuller C, Schneeberger S, Mayer G, Pratschke J, Öllinger R (2012) Recipient and donor body mass index as important risk factors for delayed kidney graft function. Transplantation 93(5):524-529

23. Hanevold CD, Ho PL, Talley L, Mitsnefes MM (2005) Obesity and renal transplant outcome: a report of the North American Pediatric Renal Transplant Cooperative Study. Pediatrics 115(2):352-356

24. Plumb LA, Pitcher D, Tse Y, Shield JP, Inward C, Sinha MD (2014) Longitudinal changes in body mass index following renal transplantation in UK children. Nephrol Dial Transplant 29(1):196-203

25. Chang SH, Coates PT, McDonald SP (2007) Effects of body mass index at transplant on outcomes of kidney transplantation. Transplantation 84(8):981-987 
26. Curran SP, Famure O, Li Y, Kim SJ (2014) Increased recipient body mass index is associated with acute rejection and other adverse outcomes after kidney transplantation. Transplantation 97(1):64-70

27. Meier-Kriesche HU, Arndorfer JA, Kaplan B (2002) The impact of body mass index on renal transplant outcomes: a significant independent risk factor for graft failure and patient death. Transplantation 73(1):70-74

28. Yamamoto S, Hanley E, Hahn AB, Isenberg A, Singh TP, Cohen D, Conti DJ (2002) The impact of obesity in renal transplantation: an analysis of paired cadaver kidneys. Clin Transplant 16(4):252-256

29. Pirsch JD, Armbrust MJ, Knechtle SJ, D'Alessandro AM, Sollinger HW, Heisey DM, Belzer FO (1995) Obesity as a risk factor following renal transplantation. Transplantation 59(4):631-633

30. Glanton CW, Kao TC, Cruess D, Agodoa LY, Abbott KC (2003) Impact of following pediatric renal transplantation. Pediatr Nephrol 25(10):2129-2139

31. Kovacs AZ, Molnar MZ, Szeifert L, Ambrus C, Molnar-Varga M, Szentkiralyi A et al (2011) Sleep disorders, depressive symptoms and health-related quality of life-a cross-sectional comparison between kidney transplant recipients and waitlisted patients on maintenance dialysis. Nephrol Dial Transplant 26(3):1058-1065

32. de Mattos AM, Prather J, Olyaei AJ, Shibagaki Y, Keith DS, Mori $\mathrm{M}$ et al (2006) Cardiovascular events following renal transplantation: role of traditional and transplant-specific risk factors. Kidney Int 70(4):757-764

33. Kasiske BL, Anjum S, Shah R, Skogen J, Kandaswamy C, Danielson B et al (2004) Hypertension after kidney transplantation. Am J Kidney Dis 43(6):1071-1081

34. Tainio J, Qvist E, Miettinen J, Holtta T, Pakarinen M, Jahnukainen $\mathrm{T}$ et al (2015) Blood pressure profiles 5 to 10 years after transplant in pediatric solid organ recipients. J Clin Hypertens (Greenwich) 17(2):154-161

35. Kaidar M, Berant M, Krauze I, Cleper R, Mor E, Bar-Nathan N et al (2014) Cardiovascular risk factors in children after kidney transplantation-from short-term to long-term follow-up. Pediatr Transplant 18(1):23-28

36. Denburg MR, Pradhan M, Shults J, Jones A, Palmer JA, Baluarte HJ et al (2010) Longitudinal relations between obesity and hypertension following pediatric renal transplantation. Pediatr Nephrol 25(10):2129-39

37. Koulouridis E, Georgalidis K, Kostimpa I, Kalantzi M, Ntouto P, Koulouridis I et al (2008) Factors influencing blood pressure control in children and adolescents. Int Urol Nephrol 40(3):741-8

38. Henry SL, Barzel B, Wood-Bradley RJ, Burke SL, Head GA, Armitage JA (2012) Developmental origins of obesity-related hypertension. Clin Exp Pharmacol Physiol 39(9):799-806

39. Parekh RS, Carroll CE, Wolfe RA, Port FK (2002) Cardiovascular mortality in children and young adults with endstage kidney disease. J Pediatr 141(2):191-197

40. Oh J, Wunsch R, Turzer M, Bahner M, Raggi P, Querfeld U et al (2002) Advanced coronary and carotid arteriopathy in young adults with childhood-onset chronic renal failure. Circulation 106(1):100 105

41. Carvalho MF, Soares V (2001) Hyperlipidemia as a risk factor of renal allograft function impairment. Clin Transplant 15(1):48-52

42. Cosio FG, Kudva Y, van der Velde M, Larson TS, Textor SC, Griffin MD et al (2005) New onset hyperglycemia and diabetes are associated with increased cardiovascular risk after kidney transplantation. Kidney Int 67(6):2415-2421

43. Hoogeveen EK, Aalten J, Rothman KJ, Roodnat JI, Mallat MJ, Borm G et al (2011) Effect of obesity on the outcome of kidney transplantation: a 20-year follow-up. Transplantation 91(8):869874
44. Hricik DE (2011) Metabolic syndrome in kidney transplantation: management of risk factors. Clin J Am Soc Nephrol 6(7):17811785

45. Laguardia H, Zhang R (2013) Obesity and metabolic syndrome in kidney transplantation. Curr Hypertens Rep 15(3):215-223

46. Zelle DM, Kok T, Dontje ML, Danchell EI, Navis G, van Son WJ et al (2013) The role of diet and physical activity in post-transplant weight gain after renal transplantation. Clin Transplant 27(4):E484 E490

47. Pham PT, Danovitch GM, Pham PC (2013) Kidney transplantation in the obese transplant candidates: to transplant or not to transplant? Semin Dial 26(5):568-577

48. Srinivas TR, Meier-Kriesche HU (2013) Obesity and kidney transplantation. Semin Nephrol 33(1):34-43

49. Hajer GR, van Haeften TW, Visseren FL (2008) Adipose tissue dysfunction in obesity, diabetes, and vascular diseases. Eur Heart J 29(24):2959-71

50. Hocker B, Weber LT, Feneberg R, Drube J, John U, Fehrenbach H et al (2010) Improved growth and cardiovascular risk after late steroid withdrawal: 2-year results of a prospective, randomised trial in paediatric renal transplantation. Nephrol Dial Transplant 25(2): $617-624$

51. Wilson AC, Greenbaum LA, Barletta GM, Chand D, Lin JJ, Patel HP et al (2010) High prevalence of the metabolic syndrome and associated left ventricular hypertrophy in pediatric renal transplant recipients. Pediatr Transplant 14(1):52-60

52. Wittenhagen $\mathrm{P}$, Thiesson HC, Baudier F, Pedersen EB, Neland M (2014) Long-term experience of steroid-free pediatric renal transplantation: effects on graft function, body mass index, and longitudinal growth. Pediatr Transplant 18(1):35-41

53. Birch LL, Davison KK (2001) Family environmental factors influencing the developing behavioral controls of food intake and childhood overweight. Pediatr Clin North Am 48(4):893-907

54. Hoffmann SW, Tug S, Simon P (2014) Child-caregivers' body weight and habitual physical activity status is associated with overweight in kindergartners. BMC Public Health 14:822

55. Litwin M, Niemirska A (2014) Metabolic syndrome in children with chronic kidney disease and after renal transplantation. Pediatr Nephrol 29(2):203-216

56. Modanlou KA, Muthyala U, Xiao H, Schnitzler MA, Salvalaggio PR, Brennan DC et al (2009) Bariatric surgery among kidney transplant candidates and recipients: analysis of the United States renal data system and literature review. Transplantation 87(8):1167-1173

57. Garness RL, Zarroug AE, Kumar S, Swain JM (2012) Laparoscopic sleeve gastrectomy in a pediatric patient. Surg Laparosc Endosc Percutan Tech 22(2):e112-e114

58. Knerr I, Horbach T, Plank C, Carbon R, Nusken KD, Rascher W et al (2003) Laparoscopically performed gastric banding in a 13 yearold girl with morbid obesity and end stage renal insufficiency allows lifesaving weight loss and hemodialysis. J Pediatr Endocrinol Metab 16(8):1179-1182

\section{Answers}

1) c

2) e

3) e

4) a

5) c 